\title{
Quality of life in a new hospital hostel
}

\author{
C. J. Simpson
}

Qualliy of life scores were measured in a new hosplta hostel in a rural community. These scores were compared to scores on patients in a similar hosplial hostel in an inner clly area in the United Kingdom and also scores on patients living in a range of different facillities in the community in the Unlited States.

The severely mentally ill do well in hospital hostels. This has been shown from a number of studies looking at symptoms of the patients (Goldberg et al, 1985) and quality of life (Simpson et al, 1989). Such hostels have developed throughout the United Kingdom (UK) over the past 15 years and are replacing the long-stay hospital beds within the National Health Service (NHS).

In Northallerton, North Yorkshire, we opened a five bedded hospital hostel, Hambleton Lodge, with psychiatric cover throughout the day and health care assistants sleeping in at night. In developing this project there was particular concern as to whether such a small hostel with staff sleeping in would be able to cater for a group of severely mentally ill patients. Therefore, the project was evaluated using similar instruments to those used in a study on a hospital hostel in Manchester (Simpson et al, 1989) and some severely mentally ill patients in the United States (Warner \& Huxley, 1993).

\section{The study}

A battery of tests were carried out on all residents prior to admission to the hospital hostel and six monthly thereafter. The following tests were carried out:

(1) The Lehman Quality of Life schedule (QOL; Lehman, 1983). This is a one hour semistructured interview in which information is obtained on personal characteristics and objective and subjective scores, as well as a global well-being score. It has recently been updated as the Lancashire Quality of Life Schedule (Oliver, 1991).

(2) Mental state and behaviour. Mental state was measured using the Manchester Scale developed by Krawiecka, Goldberg and Vaughan
(KGV; Krawiecka et al, 1977). The patients behaviour was assessed by the Social Behaviour Schedule (Wykes \& Sturt, 1986), from which the mild and severe problems score (BSM) was calculated.

(3) Staff attitudes and practices. These were assessed by using the management practices questionnaire (MP; Garety \& Morris, 1984).

Ten patients were admitted to Hambleton Lodge during the two years under study. This was a very heterogeneous group and it was decided to divide it into those who only came for assessment (Group A) and those who came for assessment and stayed (Group B). There were four patients in Group $A$ and six patients in Group B, three of whom came from long-stay hospital wards and three from their own homes. The mean of measurements for each Group B resident was used for their time at Hambleton Lodge.

\section{Findings}

The results are reported in four separate sections.

\section{Staff attitudes and practices}

The MPQ was administered twice to the two senior nurses with a 15 month interval. The results were added and the mean answer to each question was 0.07 for attitudes and 0.07 for practices. These show Hambleton Lodge to be extremely client orientated and the results are similar to the Manchester study and a hostel ward in London (Garety \& Morris, 1984). In the Manchester study on district general hospital acute psychiatric wards, the staff's attitude score was 0.27 and staff practice was 0.36; in an unstaffed group home the staff's attitude and practice scores were again far higher than in the hospital hostels. Therefore despite being a 'ward' in the community. staff attitudes and practices are geared towards individual care of the residents rather than the running of the facility. 


\section{Comparison of Group A and Group B (before Hambleton Lodge)}

It was important to see if there was a difference between those who came for assessment but were found unsuitable or were unwilling to stay and those who remained as long-term residents of Hambleton Lodge. The total KGV score (which measures total psychiatric symptoms) was higher in those who successfully stayed at Hambleton Lodge. The BSM score measuring behaviour was, however, higher in those who did not stay at Hambleton Lodge. Within the four residents of Group A two were asked to leave because of disturbing or threatening behaviour and they showed far higher KGV and BSM scores than the others. However, the two who did not wish to continue to stay at Hambleton Lodge had far lower scores.

\section{Comparison of Group B with other facilities}

The KGV scores in Hambleton Lodge for posittve and negative symptoms were higher and affective symptoms were lower than those in a similar hospital hostel in Manchester. The BSM scores were slightly higher at Hambleton Lodge and similar to a previously reported group of long-stay patients at Netherne Hospital. The US patients in intensive residential care (acute and chronic beds) were a more disturbed group than the Hambleton Lodge patients, with more positive psychotic symptoms on the KGV. However the US patients in intensive out-patient care in a form of case management showed similar levels in the KGV to the Hambleton Lodge patients. The $\mathrm{gOL}$ scores at Hambleton Lodge and Manchester were generally similar with slightly favourable subjective scores at Hambleton Lodge. The case management patients in the US did, however, also show a similar pattern of subjective satisfaction with life, although with slightly lower scores overall, especially with their living situation, finances, health and safety, but slightly higher scores in leisure activities.

\section{Group B QOL measures before Hambleton Lodge and at Hambleton Lodge}

There was a general trend of improvement in the QOL scores from before coming to Hambleton Lodge to being at Hambleton Lodge. Of note were the results of the living situation where cohesion (a measurement of residents working together within the home) and comfort showed definite improvement though the amount of influence the residents had on their living situation decreased slightly.

\section{Comment}

Interpretation of results of this study should be made with caution. The numbers are very small and so no statistical analysis could be done. In addition, all tests were administered by the author who is the consultant in charge of the residents and this could produce bias.

However, we were able to show that Hambleton Lodge was taking a very disturbed group of patients who were similar to the ones treated in a hospital hostel in Manchester. This was despite it being a smaller unit with no staff awake on duty at night. The staff attitudes and practices were appropriate and in general there was an improvement in the quality of life of the residents after their admission. The quality of life of the residents was similar to the Manchester hospital hostel. Of interest, however, were the similarities between this group and a group of patients living in a range of different facilities in the community in the US who were involved in a form of case management programme. Clearly disturbed chronic psychotic patients are treated this way in the US whereas case management is only just being developed within services in the UK. As hospital hostels are part of the recent tradition of services within the UK and case management has been developed in the US, more research is required to show which patients benefit and the relative comparative costs of each approach.

\section{References}

GARETY, P. A. \& MORRIS. I. (1984) A new unit for long-stay psychiatric patients: organisation, attitudes and quality of care. Psychological Medicine, 14, 183-192.

GOLDBERG, D. P., BRIDGeS, K., COOPER. W., et al (1985) Douglas House: a new type of hostel ward for chronic psychotic patients. British Joumal of Psychiatry, 147. 383-388.

KRAWIECKA, M., GOLDBERG, D. \& VAUghaN, M. S. (1977) A standardised psychiatric assessment scale for rating chronic psychotic patients. Acta Psychiatrica Scandinavica, 85, 299-308.

LEHMAN, A. F. (1983) The well-being of chronic mental patients. Assessing their quality of life. Archives of General Psychiatry. 40, 369-373.

OUVER. J. (1991) The soclal care directive: development of a quality of life profle for use in community services for the mentally ill. Social Work and Soctal Sctences Review. 3, 5-45.

SImpson, C. J., HYde, C. E. \& Faragher, E. B. (1989) The chronically mentally ill in community facilities. A study of quality of life. British Journal of Psychiatry. 184, 7782.

WARNER, R. \& HuXLEY, P. (1993) Psychopathology and quality of life among mentally ill patients in the community: British and US samples compared. Brttish Journal of Psychiatry, 163, 505-509.

WYkEs, T. \& STURT, E. (1986) The measurment of social behaviour in psychiatric patients: an assessment of the reliablity and validity of the SBS schedule. British Journal of Psychiatry. 148, 1-11.

C. J. Simpson, Consultant Psychiatrist, Department of Mental Health, Friarage Hospital, Northallerton, North Yorkshire DL6 IJG 